BULLETIN Bulletin hispanique

HISPANIQUE Université Michel de Montaigne Bordeaux

113-1 | 2011

Actes de 2 colloques

\title{
El mercedario quiteño Fr. José de Yepes en litigios de contrabando
}

conflictos de jurisdicción y envíos de libros en el Buenos Aires del siglo XVIII

\section{Pedro Rueda Ramírez}

\section{(2) OpenEdition}

\section{Journals}

Edición electrónica

URL: http://journals.openedition.org/bulletinhispanique/1549

DOI: 10.4000/bulletinhispanique. 1549

ISSN: 1775-3821

Editor

Presses universitaires de Bordeaux

Edición impresa

Fecha de publicación: 1 junio 2011

Paginación: 433-456

ISBN: 978-2-86781-740-3

ISSN: 0007-4640

Referencia electrónica

Pedro Rueda Ramírez, «El mercedario quiteño Fr. José de Yepes en litigios de contrabando », Bulletin hispanique [En línea], 113-1 | 2011, Publicado el 01 junio 2014, consultado el 10 diciembre 2020. URL http://journals.openedition.org/bulletinhispanique/1549; DOI : https://doi.org/10.4000/

bulletinhispanique. 1549 


\title{
El mercedario quiteño Fr. José de Yepes en litigios de contrabando: conflictos de jurisdicción y envíos de libros en el Buenos Aires del siglo XVIII
}

\author{
Pedro Rueda Ramírez \\ Universidad de Barcelona
}

Le mercédaire de Quito, F. José de Yepes fit un long voyage de pèlerinage et de collecte de fonds de Quito à la Nouvelle Espagne, et de là il partit pour l'Espagne. En 1763, il revint par Cadix et Buenos Aires avec 140 caisses dont 116 contenaient des livres. Le volume de ses achats alarma les services de contrôle et suscita un long et complexe procès dont l'étude permet l'analyse des mécanismes de la circulation et de la censure des imprimés, mais aussi des rapports de force et des rivalités qui existaient entre diverses institutions et divers individus (Inquisition, plusieurs membres de l'Ordre des Mercédaires, Vice-roi, Papauté, Conseil des Indes).

El mercedario quiteño, Fr. José de Yepes hizo un largo viaje de peregrinación y de recaudación de dinero que le llevó desde Quito a Nueva España y de alli a España. En 1763, volvió por Cádiz y Buenos Aires con 140 cajones de los cuales 116 eran de libros. El volumen de sus compras llamó la atención de los servicios de control y suscitó un largo y complejo pleito cuyo estudio permite analizar los mecanismos de la circulación y de la censura del impreso pero también las relaciones de poder y las rivalidades entre varias instituciones y personas (Inquisición, diversos miembros de la Orden de Mercedarios, Virrey, Papado, Consejo de Indias).

The Mercedario F. José de Yepes made a long journey of pilgrimage and fund raising from Quito to New Spain, and from there, he sailed to Spain. In 1763, he came back by Cadix and Buenos Aires, with 140 boxes, 116 of which contained books. The volume of his buyings caused alarm in the control services and gave rise to a long and complex

Bulletin Hispanique, Tome 113, n 1 - juin 2011 - p. 433 à 456 


\section{BULLETIN HISPANIQUE}

lawsuit, whose study allows us to analyze the mechanisms of circulation and censorship of printed matter. It also enables us to analyze the balance of power as well as rivalries that existed between the diverse institutions and individuals - the Inquisition, different members of the Order of Mercy, the Vice Roy, the Papacy and the Council of the Indies.

Mots-clés : Contrebande - Livres - Mercédaires - Buenos Aires - Quito XVIII ${ }^{\mathrm{e}}$ siècle.

«La piedra de toque donde se conocen los genios es el trato familiar y estrecho, mayormente de puertas adentro, como sucede en una navegación larga».

Antonio Porlier. Advertencias cristiano-politicas, 17571759 .

$\mathrm{L}$

A presencia del libro en Argentina en tiempos de la colonia ha sido analizada atendiendo al consumo de libros en la ciudad de Buenos Aires, la llegada de la imprenta y su expansión en tierras de misión y la formación de las colecciones, sobre todo, aquellas que contribuyeron a la formación de la Biblioteca Nacional ${ }^{1}$. Aquí nos interesa un caso singular de tráfico de libros a través de la vía de Buenos Aires, en este sentido nos interesa el libro en circulación y las redes que hacen posible el paso a territorio americano de los libros europeos que formaron el núcleo fundamental de las colecciones de las bibliotecas de todo el continente durante la edad moderna ${ }^{2}$.

1. Alejandro E. Parada, "La nueva historia del libro y las bibliotecas en la Argentina: antecedentes, historia y periodización", Congreso Mundial de Bibliotecas e Información: $70^{\circ}$ Congreso Generaly Consejo de la IFLA. Bibliotecas: Instrumentos para la Educación y el Desarrollo. 22 al 27 de Agosto del 2004, Buenos Aires, Argentina. http://www.ifla.org/IV/ifla70/prog04. htm [Consulta: 30/05/2009]. Guillermo Furlong publicó numerosos trabajos con abundante información, destaca la Historia social y cultural del Rio de la Plata, 1536-1810: el transplante cultural, ciencia, Buenos Aires: Tea, 1969, entre otros.

2. J. Torre Revello se ocupó de estos asuntos en su pionero, El Libro, la imprenta y el periodismo en América durante la dominación española, México: Universidad Nacional Autónoma de México, 1991. J. Torre Revello, «Lista de libros embarcados para Buenos Aires en los siglos XVII y XVIII», Boletín del Instituto de Investigaciones Históricas, X, 43-44, 1930, p. 28-50. Algunos trabajos también se centran en envíos de algunas órdenes religiosas, como el de Mónica P. Martini, «Los libros destinados al convento de monjas de Santa Catalina de Siena de Buenos Aires», III Congreso Argentino de Americanistas. Año 1999, Buenos Aires: Sociedad Argentina de Americanistas, 2000, t. I, p. 175-190. 
En 1763 el mercedario Fr. José de Yepes embarcó en Cádiz 140 cajones con «libros, adornos de iglesia y otros muebles para aplicarlos a su convento de Quito", llevándolos por una vía tan inusual para tal cargamento como la de Buenos Aires, lo que hizo saltar las alarmas del fiscal de la Corona ante la queja del Vicario General Fr. José de Fuente, pues «la multitud de caxones que avía conducido el enunciado religioso hacía sospechar con bastante fundamento eran para comerciar ${ }^{3}$. Armado el pleito y ateniéndose el fiscal a que era Fr. José de Yepes «artificioso y advertido» tuvo a bien continuar las averiguaciones, pues además de los cajones llevó a las Indias una serie de breves papales sin el pase del Consejo, algo que también provocó una situación delicada ordenándose su recogida. Ante tal perspectiva Fr. José de Yepes se encontró en una peculiar disyuntiva, pues los breves le concedían toda una serie de privilegios que chocaban con los intereses de otros miembros de la orden. Ahora bien, llevarlos a su destino sin el pase del Consejo de Indias podía colocarlo en una situación delicada ante las autoridades de la Corona. En esta situación de doble conflicto se encontraba en 1763, por una parte con los miembros de su orden y con el Vicario General de la misma, y por otro lado con las autoridades coloniales, con el gobernador de Buenos Aires a la cabeza en representación del rey y el propio Consejo de Indias a través del fiscal encargado de su caso. Un resumen claro del asunto es expuesto al General de los mercedarios por Fr. José de la Fuente que le explicó que llevaba «inmensa carga que conduce de España de toda especie de géneros con el especioso título de que los trahe no para comerciar sino para beneficio de su convento y otros y que los ha comprado con el dinero que ha recogido de las limosnas que le han ofrecido los fieles de ambas Américas en la peregrinación que ha hecho por ellas con Ntra. SSma. Madre» ${ }^{4}$. Lo cual es cierto, pues viajó con una imagen de la Virgen en peregrinación recogiendo limosnas por ambos virreinatos, tanto en el Perú como en Nueva España, antes de viajar a España.

Lo interesante del caso es cómo pudo Fr. José de Yepes articular su defensa recurriendo al cabildo bonaerense, a miembros de su orden en la provincia o

3. Archivo General de Indias (AGI). Quito, 288, nº 7. El pleito contra Fr. José de Yepes es la base fundamental de este trabajo, es un grueso expediente sin foliar del que se han extraído buena parte de las citas que traeremos a colación aquí. Del contrabando en términos generales nos ocupamos en P. Rueda Ramírez, "El contrabando de libros en la Carrera de Indias: una faceta poco conocida del comercio del libro», Testigo del tiempo, memoria del universo. Cultura escrita y sociedad en el mundo ibérico (siglos XV-XVIII), comp. Manuel F. Fernández, C. A. González Sánchez, N. Maillard, [Barcelona]: Ediciones Rubeo, 2009, p. 153-174.

4. Archivo Histórico Nacional (AHN). Diversos, 37, n. 39. Carta desde Arequipa, 176504-12. 
al obispo de Buenos Aires, que escribieron en su favor, para defenderse de las acusaciones de que se aprovechó de su estado religioso para entrar mercancías para la venta y de actuar contraviniendo las normas jurídicas de la Corona en relación a los breves papales. En esta enredadísima situación legal el fraile logró desmontar la acusación de contrabandista y de beneficiarse de la venta de libros y otros bienes, además de lograr articular una defensa frente a la otra grave acusación de llevar sin pase los breves. Entre tanto pasaron varios años y se generó un conflicto interno con los mercedarios llegando a intervenir al General de la Orden. El conflicto de jurisdicciones, en cierto modo, le permitió manejarse en una situación tan delicada, moviéndose entre dos jurisdicciones, defendiéndose de todas las acusaciones y logrando mejorar su posición dentro de la orden. No le faltaron detractores ni enemigos, pero también logró articular toda una muralla protectora en forma de cartas favorables y una red clientelar que le sostuvo en sus cargos o le permitió promocionarse. A pesar de sus evidentes contradicciones y las sospechas que levantó logró acallar a lo largo del pleito con la Corona una parte de las voces de los enemigos con un constante caudal de papeles.

\section{El viaje de ReCAudación: De QUito A ESPAÑa}

El propio Fr. José de Yepes, para argumentar su defensa, pidió que se interrogara detalladamente y sobre las cuestiones que le interesaban a Fr. Pedro Saldaña «compañero inseparable que fue de mi peregrinación así en la Nueva España como en Buenos Aires después de mi regreso de los reynos de Castilla $»^{5}$. Esto nos permite averiguar ciertos detalles de su viaje, que se justificó por la «colección de limosnas para esa hermita» de San José y la necesidad de recaudar dinero para viajar a Espańa y pedir «en la Corte las licencias de el Rey para la fundación del convento en dicha hermita y conducir misioneros ${ }^{6}$. En el viaje, Yepes procuró pertrecharse de todos los medios de justificación que le permitieran desarrollar la peregrinación y obtuvo del papa Clemente XIII un breve que le autorizaba a llevar un altar portátil en su viaje por Nueva España ${ }^{7}$ El argumento del viaje de ida desde Quito para reunir limosnas, conseguir licencia de fundación en Espańa, etc. estaba bien trabado y le permitió recorrer los caminos americanos. Algo más difícil era justificar adecuadamente las cuentas, pero más que este asunto (que no quedó nada claro) o la propia peregrinación nos centraremos en un

5. AGI. Quito, 288, no 7.

6. AGI. Quito, 288, no 7.

7. AGI. MP-Bulas, Breves, 481. 
par de cuestiones que pueden ayudar a entender algunos detalles del éxito del viaje. En el momento de su salida de Quito llevó consigo una imagen de la Virgen de la Merced conocida como La Peregrina, esto le permitió a lo largo de su recorrido ofrecer misas y recibir limosnas con gran facilidad. El problema básico era que se suponía que las limosnas recogidas se destinarían a la Ermita de San José. A tenor del interrogatorio Fr. José de Yepes uso en su viaje todos los medios propios de un mercader a lo divino para mover a la devoción en sus misiones. En la pregunta décima se preguntó a Fr. Pedro de Saldaña «si sabe y le consta que don Josef y don Vicente de Ojeda y Estrada eran mis correspondientes antiguos en la Puebla de los Ángeles y don Miguel Lazo de la Vega en la Veracrus, puerto de la Nueva España, y que de ellos me valía para varios encargos y compras de medallas, cruzes y otros efectos para la postulación en tan gruesas cantidades que huvo ocasión en que se compraron por su mano cien mil y la listoneria de diversos anchos para satisfacer la devoción de los fieles con medidas de la Santa Ymagen» ${ }^{8}$. Es un claro ejemplo de compra al por mayor a importantes mercaderes poblanos que recibían esta quincallería religiosa con frecuencia embarcada en la flota de Nueva Espańa. Lo que más nos interesa es comprobar, como podíamos sospechar, que utilizó las prensas para promocionar su causa, así pide Yepes que le pregunten a Fr. Pedro de Saldaña si acudió a los ya citados "para la impresión de gruezas cantidades de estampas de todos tamaños, novenas y otros devocionarios en tanta copia, que después de dar abasto a toda la peregrinación el declarante conduxo muchos caxones a dicha hermita de los que reparte hasta oy entre los fieles después de haber llenado toda la provincia y la de los Pastos y Barbacoas», señalando que «bien es que en gran parte se estamparon e imprimieron ygualmente en México». A lo cual Fr. Pedro de Saldaña al leérsele esta pregunta en 1768 responde «que era cierto todo lo contenida en ella». Es más, cuando acompañaba la peregrinación Fr. José de Saldaña tenía algunos bienes que «se consumieron por el uso» y los declara, por ejemplo, «un misal nuevo que después de haver servido en la peregrinación y en dicha hermita llevó el declarante a Buenos Ayres y hasta Mendoza, donde por serle inútil y estar ya muy usado lo dexó en poder» de Fr. José de Yepes. Al igual que anota unas «láminas, escudos de bronze para sacar estampas de todos tamańos que costaron seiscientos pesos dice el declarante se consumieron». Esto último es interesante, pues en otra declaración de 1759 el propio Fr. José de Yepes declara la «memoria de lo que entregó el P.M.Fr. Josef de Yepes y Paredes, perteneciente a la limosna que la Serenísima Virgen recojió para la recolección y colegio de mición

8. AGI. Quito, 288, nº 7. 
[i.e. misión] del Texar de la Merced de la ciudad de Quito", con los bienes que entregó a Fr. José de Saldaña «en este pueblo de Yzúcar, caminando para el puerto de Acapulco», en el que efectivamente aparecen tanto el «misal nuevo y un lente que vulgarmente llaman titiliimundi» como las «láminas de bronze y escudos, para sacar estampas, y escudos para el mismo fin»" Se dio cuenta de la facilidad con la que se podían imprimir estampas a partir de las planchas calcográficas, de este modo cualquier prensa podía realizar las cantidades necesarias para llevarlas en la peregrinación ambulante, una aventura devota y comercial que recorría cientos de kilómetros visitando innumerables ciudades y pueblos con la imagen de la Virgen. El uso de las prensas para mover a devoción, generar afectos y emociones, bien en el auditorio que asistía a la misa o entre los lectores que se llevaban librillos y papeles impresos, fueron fenómenos muy comunes a ambos lados del Atlántico. Una suerte de pedagógica devota que los misioneros conocían a la perfección y aplicaban habitualmente ${ }^{10}$.

\section{El viaje de vuelta: DE CÁdiz a Buenos AIRES}

La elección de la vía de Buenos Aires para un cargamento de 140 cajones destinados a Quito alarmó a las autoridades coloniales. Otros religiosos que viajaron a Quito en la misma época indicaron las rutas más usuales y no incluían la de Buenos Aires. En 1749, el jesuita Bernardo Recio realizó la ruta atlántica y cuando escribió el relato de su viaje en Girona en 1773 (una vez expulsados los miembros de la Compañía de Jesús de América) indicó «los tres rumbos que pueden seguir los que se encaminan a Quito» ${ }^{11}$. El primero consistía en navegar hasta Cartagena, seguir la ruta por el río Magdalena y por tierra a través de Monpox, Popayán, Pasto «y aunque el camino es muy dilatado se hace más fácil por lo poblado y ameno»; el segundo, que Recio y los 49 jesuitas que lo acompañaban siguieron, era el tradicional paso del istmo de Portobelo a Panamá, para embarcarse en esta ciudad con destino a Guayaquil desde donde "pasando el río y montes altísimos, por Ríobamba, Ambato y Tacunga, se logra un camino llano, plácido y deleitable» hasta

9. AGI. Quito, 288, nº 7.

10. F. Palomo, «Limosnas impresas. Escritos e imágenes en las prácticas misioneras de interior en la Península Ibérica (siglos XVI-XVIII)", Manuscrits: Revista d'història moderna, 25, 2007, p. 239-265.

11. B. Recio, Compendiosa relación de la cristiandad de Quito, Madrid: Consejo Superior de Investigaciones Científicas, Instituto Santo Toribio Mogrovejo, 1947, p. 93. 
Quito; el tercero que apunta Recio era «rumbo por el Marañón, bajando río abajo al país de los portugueses» ${ }^{12}$.

Era habitual encontrar algunos libros entre los bienes de los pasajeros que sabían leer y no era nada rara la lectura en voz alta para todos aquellos que querían pasar un rato entretenido ${ }^{13}$. Los textos de literatura, las vidas de santos y la devoción permitían pasar los días de viaje algo más ocupados. Aunque los libros que nos ocupan iban como parte de un lote encajonado y cerrado, como una mercancía más, lo que era bastante habitual. Tras un tiempo sin salidas los barcos que acudían a Tierra Firme en 1706 transportaban ciento setenta y un cajones de libros ${ }^{14}$. En los momentos de la Guerra de Sucesión el tráfico comercial resultó interferido por las luchas en el Atlántico, pero no podemos olvidar lo que Malamud Rikkes denominaba el comercio directo, que permitió el tráfico de mercancías desde diversos puertos europeos franceses a los puertos americanos sin recalar en Espańa. Entre las mercancías que el capitán del navío francés San Francisco distribuyó en Lima en 1707 se encontraban «libros diferentes» que incluían «Breviarios, Misales, Ramilletes y obras de Quevedo, temporal y eterno y otros muchos como Torrecillas, Corellas, Sylveyra, Cornelios» ${ }^{15}$. Estos fueron libros comunes en el negocio de librería que, en este caso, se remitieron a América a través de un navío francés. Estos libros transportados de manera legal o de contrabando en baúles y cajones encerados, resguardados de las inclemencias y de las filtraciones de agua en el navío, fueron clave en el abastecimiento de libros en los virreinatos, pues los libros que llevaban los viajeros atlánticos en sus petacas eran apenas unos títulos destinados a ocupar un tiempo de espera rutinario y repetido, con un elevado riesgo diario ante la enfermedad, las tormentas o los piratas ${ }^{16}$. Una parte importante de las bibliotecas particulares viajó como parte de la carga. Antonio Porlier viajó desde Cádiz a Montevideo en 1759 con un lote de libros importante, al llegar a su puesto como fiscal de indios en la Audiencia de Charcas sus bienes se tasaron y se contabilizaron

12. B. Recio, Compendiosa relación.., p. 93-94.

13. Irving A. Leonard, «Spanish Ship-Board Reading in the Sixteenth», Hispania, 32, 1, 1949, p. 53-58.

14. C. R. Phillips, «Mercado, modas y gustos: los cargamentos de ida y vuelta en el comercio atlántico de España», España y América: Un océano de negocios. Quinto centenario de la Casa de la Contratación, 1503-2003, [Madrid]: Sociedad Estatal de Conmemoraciones Culturales, 2003, p. 199-200.

15. C. D. Malamud Rikles, Cádiz y Saint-Malo en el comercio colonial peruano (16981725), Cádiz: Diputación, 1986, p. 348.

16. C. A. González Sánchez, «La Casa de la Contratación y la historia cultural», La Casa de Contratación y navegación entre España y las Indias, coords. Antonio Acosta Rodríguez, Adolfo Luis González Rodríguez, Enriqueta Vila Vilar, Sevilla, 2004, p. 543-566. 
1.146 volúmenes en su biblioteca. Libros que habían viajado con él desde Espańa cuando fue a ocuparse del puesto ${ }^{17}$.

En la segunda mitad del siglo XVIII la bahía de Cádiz mantenía un peso clave en el tráfico comercial con América, incluso después de la apertura de otros puertos en los ańos que van de 1765 a 1778. En 1787 la Aduana de Cádiz representaba el $48 \%$ de los derechos aduaneros recaudados en España que alcanzaban en conjunto los 171.335 .218 reales de vellón ${ }^{18}$. En lo que se refiere a la presencia de libros en los navíos que viajaron a Buenos Aires podemos evaluar una muestra de 50 navíos que viajaron bajo registro entre 1721 y 1758. En ellos aparecen libros en un total de 27 navíos (54\%) que suman 1.057 cajones, 4 baúles, 1 cofre, 1 tercio y 457 ejemplares $^{19}$. El resultado es interesante teniendo en cuenta que son una muestra de barcos con las mercancías declaradas, siguiendo el mismo procedimiento que llevó a Fr. José de Yepes ante las autoridades aduaneras para cumplir con los trámites. En el navío de registro Jesús, María y José que viajó en 1750 iban 84 cajones de libros, y en el registro del navío negrero San Francisco Javier se declararon 124 cajones de libros. El mayor número de cajones de esta muestra fueron los 183 cargados en el registro del navío San Antonio de Padua en 1752. El envío de Fr. José de Yepes de 140 cajones (116 de ellos con libros) lo sitúa entre los más elevados, pues la media de los 27 navíos que fueron a Buenos Aires, ya citados, es de 40 cajones de promedio y tan solo en dos casos se superan los cien cajones (183 en 1752 y 124 en 1755). Una vez abiertos otros puertos peninsulares al Comercio Libre con el puerto de Buenos Aires las posibilidades de llevar libros se incrementarían, sin que el peso de Cádiz remitiera, pues mantuvo importantes y bien surtidas librerías con un fondo notable ${ }^{20}$. Es interesante constatar como en fechas tan tempranas como mayo de 1778 en Málaga se abría el registro de una saetía catalana denominada San Isidro con destino a Buenos Aires (la segunda nao que salía hacia esta provincia desde el puerto malagueño), en sus bodegas

17. D. Rípodas Ardanaz, Un ilustrado cristiano en la magistratura indiana: Antonio Porlier, Marqués de Bajamar. Viaje de Cádiz a Potosí (1758-1759), Buenos Aires: PRHISCOCONICET, 1992, p. 28.

18. J. Muñoz Pérez, «Mapa aduanero del XVIII español», Estudios geográficos, 16, 61, 1955, p. 793.

19. M. J. Arazola Corvera, Hombres, barcos y comercio de la ruta Cádiz-Buenos Aires (17371757), Sevilla: Diputación, 1998, p. 381-389.

20. F. López, «Geografía de la edición. El comercio interior y exterior», Historia de la edición $y$ de la lectura en España, 1472-1914, Madrid, 2003, p. 338-347. M. L. López-Vidriero, «Le rôle de l'Espagne dans le commerce du livre au XVIII siècle», Le Livre voyageur: constitution et dissémination des collections livresques dans l'Europe moderne, 1450-1830, éd. Dominique Bougé-Grandon, Paris: Klincksieck, 2000, p. 129-151. 
llevaba libros con textos de entretenimiento, historia, política, teología y filosofía destinados a su venta en la provincia bonaerense ${ }^{21}$.

El viaje de Yepes en 1763 se enmarca en un momento crítico de los debates en torno a la libertad de comercio con América. En los años 17501765 se redactaron numerosos memoriales y discursos como el de Pedro Flores Silva de 1752 en el que advertía al Rey de la necesidad de una mayor liberalización del comercio para que no «bastardee la lealtad» ni «en los vasallos desfallezca el ánimo ${ }^{22}$. En el caso bonaerense la transgresión de las leyes era algo perfectamente asentado en el trato comercial. Los trabajos de Moutoukias revelan como entre 1658 y 1702 llegaron al Río de la Plata 34 navíos de registro que cumplieron con los trámites y 124 navíos que recalaron al margen del sistema legal. Estos últimos fueron en su mayoría barcos extranjeros, la mitad de ellos naves holandesas, pero también recalaron navíos españoles que acudieron al puerto bonaerense al margen del sistema de licencias sueltas otorgadas por la Corona ${ }^{23}$. Es algo que el viajero Acarette observó con detalle al viajar (de forma ilegal como extranjero) en 1657 desde Cádiz a Buenos Aires, para él en la ribera del Río de la Plata «toutes sortes de vaisseaux y aillent trafiquer sans permission $»^{24}$.

A lo largo del siglo XVIII los intereses de los comerciantes y hacendados limeños fueron clave para frenar el desarrollo de compañías comerciales destinadas a Buenos Aires, de este modo se reforzaba la feria de Puertovelo y el sistema tradicional de flotas. Incluso el Presidente de la Casa de la Contratación en 1720 aseguraba al Marqués de Castelfuerte, Virrey del Perú, que la intención del Rey era limitar el registro a Buenos Aires a los productos necesarios en las provincias de Buenos Aires, Tucumán y Paraguay ${ }^{25}$. De todos modos, el proyecto de galeones que intentó en 1720 reorganizar el sistema de flotas favoreció al puerto bonaerense, pues facilitó la llegada de navíos de aviso y la concesión de licencias, como la de 1721 que permitió la llegada de dos navíos y una fragata con mercancías que no pagaron en Buenos Aires más que la alcabala y contaron con autorización para introducir en la

21. H. Asdrúbal Silva, El comercio entre España y el Río de la Plata (1778-1810), Madrid: Banco de España, 1993, p. 64.

22. M. E. Rodríguez García, Compañias privilegiadas de comercio con América y cambio político (1706-1765), Madrid: Banco de España, 2005, p. 65.

23. Z. Moutoukias, Contrabando y control colonial en el siglo XVII: Buenos Aires, el Atlántico y el espacio peruano, Buenos Aires: Centro Editor de América Latina, 1988, p. 126.

24. Acarete, du Biscay, Voyage dv Sr. Acarette a Bvenos-Ayres svr la Riviere de la Plate, \& delà au Perou. Et l'Indien ov portrait av natvrel des Indiens presenté au Roy d'Espagne par D. Iüan de Palafox Evesque de la Puebla de los Angeles, A Paris: Chez André Cramoisy, 1672, p. 19.

25. M. E. Rodríguez García, Compañias privilegiadas de comercio con América, p. 46. 
Audiencia de Charcas y el Reino de Chile ropa por valor de 700.000 pesos $^{26}$. El riesgo del contrabando con los productos que llevaba Yepes se enmarca en este contexto general y la situación periférica de Buenos Aires, en un área tradicionalmente ligada a la entrada de mercancías extranjeras a través de colonias como la de Sacramento ${ }^{27}$. En 1763, precisamente, el gobernador y capitán general de las provincias del Río de la Plata y ciudad de Buenos Aires, tras la firma del Tratado de París el 10 de febrero de 1763 entregó la "plaza de la Colonia del Sacramento» a los portugueses, que la utilizaron como hicieron los ingleses a principios del siglo XVIII para facilitar el contrabando $^{28}$. Al menos hasta la llegada del primer virrey Pedro de Cevallos, pues una de las finalidades de la creación del Nuevo Virreinato del Río de la Plata en 1776 fue eliminar esta colonia y consolidar el área económica bonaerense con la libre apertura a la navegación y el comercio el 2 de febrero de 1778.

Esta particular situación de transición del comercio de licencias de registros sueltos y el sistema de correos de avisos a la apertura comercial es la que vivió Fr. José de Yepes en los años del litigio, que se alargó por varios vericuetos hasta 1780. El celo del fiscal de la Corona ante un caso potencial de comercio ilícito se sumó el estado religioso del fraile que podía complicar aún más el asunto al implicar problemas de jurisdicción. Aunque no fue el único que sospechó de las intenciones del fraile. El bailío frey Julián de Arriaga el 9 de junio de 1763 escribió desde Aranjuez sobre la petición de licencia para regresar a Quito de Fr. José de Yepes con «un donado que trajo, y embarcar un criado natural de estos reinos, como asimismo varios géneros para ornamentos y otros husos de los religiosos». El asunto (por el cariz que tomaba) no gustó a Arriaga, ante lo cual indicó a los oficiales de la Corona en Cádiz que «no asiente S. M. a que lleve el criado, ni que embarque libre de derechos más que lo que va con esta expresión en la adjunta nota rubricada de mi mano, pues de lo restante deverá satisfazer los señalados y que están en práctica ${ }^{29}$. El donado era Antonio Castañeda, un joven de 24 años del Real del Monte en la jurisdicción de Pachuca de Nueva España, que le acompañó

26. S. Villalobos R., Comercio y contrabando en el Río de la Plata y Chile, 1700-1811, Buenos Aires: Editorial Universitaria de Buenos Aires, 1965, p. 39.

27. Ma Dolores G. Molleda, «El contrabando inglés en América: correspondencia inédita de la factoría de Buenos Aires», Hispania, 10, 39, 1950, p. 336-369.

28. C. Calvo, Colección completa de los tratados, convenciones, capitulaciones, armisticios y otros actos diplomáticos de todos los Estados de la América Latina comprendidos entre el Golfo de Méjico y el Cabo de Hornos, desde el año de 1493 hasta nuestros días [1862], Vaduz: Topos Verlag, 1978, p. 384-386.

29. AGI. Contratación, 5506, n. 1, r. 34, f. 1. 
en su viaje a España en 1760. El 3 de octubre de 1763 el P. Yepes lograba la licencia para él y para su donado para ir en el navío El Príncipe San Lorenzo a Buenos Aires. Conseguidos los papeles relativos a ambos quedaba embarcar las mercancías, sin que sepamos que ocurrió con la «nota adjunta» del bailío, pues no se ha conservado en el expediente de licencia de pasajero a indias. En estas cuestiones de las declaraciones detalladas de lo que va y viene de América algunos cronistas bien informados, como el sevillano Diego Ortiz de Zuñiga, no dejan de recalcar que la finalidad de la Casa de la Contratación y de sus agentes era controlar lo tributado de oro y plata, perlas, esmeraldas y otros géneros, sin que le quepa duda de que «muchos lo han querido reducir a guarismo [...] pero lo cierto es que muchísimo más es lo que de cierto no se sabe» ${ }^{30}$.

Fr. José de Yepes cargó los 141 cajones en el navío El Príncipe San Lorenzo tal como queda de manifiesto en la copia de las dos partidas de registro que se copiaron en el pleito que estamos citando a partir de los originales guardados en la Contaduría de la Casa de la Contratación, tal como era preceptivo según sus Ordenanzas. En la primera partida registró nuestro fraile «por su quenta y riesgo y para entregarle por ser efectos comprados con su propio caudal» un tercio (con 64 piezas de bretaña), 6 marquetas de cera (de a diez arrobas) y cinco baúles en los que iban los ornamentos (una colgadura de damasco, un dosel para altar mayor, casullas, capas de coro, etc.). En la otra partida de registro también iban telas en dos tercios y tres cajones, además de "dos frasqueras de a quatro en carga con licores», y por primera vez en el pleito tenemos una información certera del total de libros, pues frente a las generalizaciones de los testigos que declaran en Buenos Aires tenemos una relación genérica del total de cajones con libros, se anotan:

Ciento diez y seis caxones de libros vistos por el Santo Oficio de porte de a media carga.

Un quintal de hilo salo para estiuar dichos cajones.

Un cargo de a carga con estampas, rezo y otros impresos vistos igualmente por el Santo Oficio todo lo dicho lleua la marca del margen $^{31}$.

30. D. Ortiz de Zuñiga, Anales eclesiásticos y seculares [1796], Sevilla: Guadalquivir, 1988, t. IV, p. 109.

31. AGI. Quito, 288, no 7. Una narración del viaje con idéntico itinerario al desarrollado por Fr. José de Yepes fue contado por Antonio Porlier en su Jornal de un viaje a Buenos Aires desde Cádiz empezado en 3 de agosto de 1758. Transcrito por D. Rípodas Ardanaz, Un ilustrado cristiano en la magistratura indiana: Antonio Porlier, Marqués de Bajamar. Viaje de Cádiz a Potosi (1758-1759), Buenos Aires: PRHISCO-CONICET, 1992, p. 143-172. 
La marca es el escudo de la orden mercedaria, algo frecuente en los envíos de las órdenes, o incluso en envíos de libreros que remiten libros a conventos americanos, por ejemplo, en 1613 Antonio de Toro remitió al convento de San Agustín de Puebla de los Ángeles un lote de 61 títulos usando la marca de un corazón atravesado para identificarlos con más facilidad ${ }^{32}$.

No contamos con la memoria de los títulos embarcados, se indica que fueron "vistos igualmente por el Santo Oficio», es decir, que la lista de obras se presentó ante las autoridades inquisitoriales y fue revisada por un calificador. La ristra de títulos anotada en las memorias se verificaba por el calificador comparando con índices de libros prohibidos y edictos, pero no se comprobaba siempre la lista presentada con lo que se encontraba en los cajones. Los comisarios inquisitoriales se quejaron de la falta de cuidado de los cargadores al elaborar las memorias y la poca colaboración que mostraban las cinco librerías abiertas en Cádiz a mediados del XVIII. En ocasiones, la técnica para ocultar libros prohibidos era sencilla: el cargador enviaba una carta al destinatario advirtiendo cuáles eran los libros que enviaba realmente y elaboraba otra lista, ésta falsificada, al menos en parte, con títulos inocuos que era presentada al comisario inquisitorial para obtener el pase a Indias, tal como pudo demostrar Ripodas Ardanaz en el análisis de un pleito que reveló la llegada de un pequeño lote de libros prohibidos pedidos por un funcionario de la Corona ${ }^{33}$.

Los cajones remitidos por Yepes llegaron sin que una vez desembarcados se abrieran, ya que no era práctica corriente su apertura, sin contar con sospechas evidentes. Incluso en algunos casos de dudas de las autoridades y ante la posibilidad de perder la carga eran los propios mercaderes los que proponían una composición con los arrendadores o la Corona. De este modo la concertación de los jueces de comisión encargados de vigilar la entrada con los mercaderes locales permitía, como ocurrió en Cartagena en 1587, que el oficial real «no abriese ni desempacase fardos ni cajas» ${ }^{34}$.

La carga llegó al puerto el 5 de febrero de 1764 y Fr. José de Yepes se dirigió al convento «de San Ramón de Buenos Ayres, provincia de Tucumán», donde sus hermanos de orden le recibieron con hospitalidad, y él correspondió beneficiando a «la sachristia dando una rica casulla bordada sobre raso encarnado, con oro, plata y sedas en muestra de su gratitud ${ }^{35}$.

32. AGI. Contratación, 1160, N. S. de los Remedios, fol. 112r.

33. D. Rípodas Ardanaz, «Introducción fraudulenta de libros prohibidos en el Río de la Plata (1788)», Revista de historia del derecho, 28, 2000, p. 503-512.

34. M. Ulloa, La Hacienda Real de Castilla en el reinado de Felipe II, $3^{\text {a }}$ ed. revisada, Madrid: Fundación Universitaria Española, 1986, p. 708.

35. AGI. Quito, 288, no 7. Buenos Aires, 12 de diciembre de 1764. 


\section{Los ENEMigos}

Fr. José de la Fuente, Vicario General de los mercedarios, viajó en el mismo navío que Yepes con destino a Buenos Aires, según algunos testigos una diferencia entre ambos al final del viaje desencadenó una enemistad tan profunda que llevó a la acusación y al pleito contra Yepes. El asunto es, sin duda, más enrevesado, pues el propio Vicario General apenas está presente en el pleito y su testimonio queda en gran medida diluido. Ahora bien, sabemos que mantuvo una notable correspondencia con los generales de su orden para comunicarles el caso. En la colección de documentos diversos de Indias del Archivo Histórico Nacional de Madrid se conservan las cartas de Fr. José de la Fuente en las que desgrana sus sospechas contra Fr. José de Yepes. En 1766 escribe al General acusándole de mantener una «vida licenciosa» dedicada al "comercio público en todo género de mercaderías, reprobado por todo derecho y causando en estos países el escándalo que ocasiono en su reyno a toda clase de gente», además de ser de "perverso genio, para persuadir a algunos sujetos de estos Reynos que le persigo y no le permito dicha peregrinación por aprovecharme de su carga ${ }^{36}$. El objetivo del P. Fuente era el retorno de Yepes a Quito, tal como había ordenado el General de la orden que había escrito al rey informándole de esta decisión. Este era para Fuente el único medio de lograr que la carga llegara a su destino. Otro problema era la permanencia de Yepes durante varios años en Buenos Aires dedicado aparentemente a misiones y a tareas totalmente acordes a su estado, aunque para el Visitador andaba enredando en los conventos de la orden y provocando disturbios que en 1768 llevaron a una revuelta en la que Yepes con otros llegó a formar capítulo aparte e intento el arresto del provincial. El obispo de Buenos Aires fue un observador directo de estos asuntos y escribió al rey una extensa carta. Las discordias entre Fr. José de Yepes y el visitador de la orden «fueron creciendo» hasta que «el capítulo provincial que se celebró en la ciudad de Córdoba con indecibles escándalos, y no sin notorias nulidades». El obispo resume perfectamente el principal problema de Yepes ya que tenía que pagar los gastos del flete. Tenía el «registro depositado y custodiado en poder de los sugetos que le han prestado el dinero de los fletes, a cuya paga les hypotecóm ${ }^{37}$. De otro modo lo veían los enemigos de Yepes. Este habría recibido de un funcionario de la

36. AHN. Diversos, 37, n. 39.

37. AGI. Quito, 288, no 7. El obispo de Buenos Aires al rey. Buenos Aires, 15 de enero de 1768. 
Corona un total de «ocho mil pesos fuertes, que solo puede satisfacerselos vendiendo sus géneros y comerciando como un secular, a cuio efecto le han embargado la carga solicitando que la venda para el seguro pago de dicha cantidad lo que sólo puede executar con interés, vendiendo sus géneros con reputación, permitiéndole la expresada continuación en su antigua vida ${ }^{38}$.

El 10 de junio de 1766 el Consejo de Indias toma cartas en el asunto y el Marqués de los Llanos escribe a Basilio Gil de Bernabé, General de la orden de la Merced, que «la excesiva multitud de caxones que por el testimonio que incluye este religioso consta conduxo hace sospechar con bastante fundamento que los libros, adornos de iglesia y demás contenido en ellos, no se compraron aquí para los conventos de su provincia, sino para exercer un comercio prohibido por derecho canónico a los eclesiásticos y especialmente a los religiosos ${ }^{39}$. Las acusaciones de Fr. José de la Fuente fueron tergiversadas por el propio Yepes al informar al Consejo de Indias, pero como vemos los consejeros tenían su propia opinión y sospechaban que llevó los cajones por Buenos Aires y no por la vía de Cartagena para «dar con la mayor distancia más excesivo precio a aquellos efectos», ante lo cual solicitan al General «averiguar y corregir» sobre el asunto ${ }^{40}$. La respuesta de Fr. Basilio Gil de Bernabé fue dar órdenes para que Yepes volviera a Quito y no saliera nunca más de allí, aunque como veremos dio largas a su vuelta y además pidió autorización para salir de nuevo en peregrinación. La resistencia y la oposición a la autoridad de Yepes alcanzaron así el nervio mismo de la orden, generando una dura respuesta que no encontró manera de concretarse. En todo caso, no era el primer fraile rebelde que fue tildado de contrabandista, en el bando de 29 de marzo de 1748 el cabildo de Buenos Aires se declaran los tejemanejes de varios mercaderes y de Fr. Juan Antonio de Amezaga que al entrar en la ciudad declaró 16.000 pesos (una cantidad notable), pero de él se sospechaba que sacó por la colonia de Sacramento el doble, evidentemente negociando con los mercaderes, muchos de ellos portugueses e ingleses, que introducían toda clase de mercancías y esclavos ${ }^{41}$. La Corona insistiría en la necesidad de erradicar el trato ilícito, tal como manifestó José de Gálvez en 1776 en su afán reformista, para que cada empleado público «con el mayor desvelo se dedique a perseguir los continuos

38. AHN. Diversos, 37, n. 39.

39. AHN. Diversos, 40, n. 65, fols. 2r-v.

40. AHN. Diversos, 40, n. 65, fols. 3r.

41. M. J. Arazola Corvera, Hombres, barcos y comercio de la ruta Cádiz-Buenos Aires (1737-1757), Sevilla: Diputación, 1998, p. 211. Las redes y contactos entre los hombres del comercio pueden seguirse en el estudio de M. J. Arazola Corvera, «El mundo del comercio vasco-navarro en la ruta del Plata. Los registros sueltos", Itsas Memoria. Revista de Estudios Maritimos del País Vasco, 4, 2003, p. 327-342. 
fraudes que se hacen contra los justos derechos de su Real Hacienda ${ }^{42}$. En esta situación de refuerzo de la autoridad en el control del comercio colonial y en la ampliación de la jurisdicción real debemos situar el pleito de Yepes y el afán del fiscal siguiendo la pista a las posibles pruebas.

El asunto de la participación en tales negocios era claro en el derecho canónico, y sobre ello el obispo de Buenos Aires había escrito unas recomendaciones claras. En el caso de los clérigos lo adecuado era «ni riquezas, ni mendicidad", pues sería motivo de escándalo tener que "pasar del servicio del Altar al servicio del campo, como un jornalero infeliz», y sería doloroso para el prelado ver a un ordenado en el comercio divino dedicado al trato y contrato: « $i$ desde el comercio admirable, que debe tener Dios, y sus Ángeles, al comercio y negociación propia de tratantes y hombres del mundo? ${ }^{43}$ " La Carta circular (Buenos Ayres, 1781) de José Antonio de San Alberto no dejaba dudas en esto y determinaba la necesidad de un beneficio eclesiástico para el clero. La dedicación piadosa a misiones de Fr. José de Yepes correspondía con su papel de religioso, pero las denuncias de aventuras comerciales no podían beneficiarle en modo alguno en este contexto. Aunque la teoría tridentina y las buenas palabras del obispo intentaban corregir y enmendar prácticas cotidianas del clero, estas debían ser sobradamente conocidas en la ciudad. Tales aventuras comerciales de los eclesiásticos bonaerenses podían generar escándalo pero, probablemente, no sorpresa o, como es nuestro caso, resultaba compatible una aparente vida de perfección (según unos testigos) a la par que un cúmulo de sospechas de contrabandista (según otros). En 1765 Fr. José de la Fuente, vicario general, escribía desde Arequipa al padre general de la orden de la Merced para advertir de Fr. José de Yepes del que afirma es de "genio díscolo, atrevido», ya que intentó «persuadir a algunos sujetos de estos Reynos que le persigo». El problema era que el vicario general bonaerense no le concedió licencia para peregrinar ya que sospechaba que «dicho P. continuase en su vida licenciosa y en un comercio público en todo género de mercaderías», ante lo cual Fr. José de Yepes enredó en el capítulo provincial ${ }^{44}$.

42. El contrabando y el comercio exterior en la Nueva España, nota preliminar de Ernesto de la Torre Villar; advertencia de Luis Chácez Orozco, México: Publicaciones del Banco Nacional de Comercio Exterior, 1967, p. 158.

43. Carta circular, ò edicto, de el ilustrisimo, y reverendisimo señor D. Fr. Josef Antonio de S. Alberto, del consejo de S. M. y obispo de Cordova del Tucuman: dirigida a todos sus amados hijos, y diocesanos, que desean, y solicitan, y que en adelante solicitaren ser promovidos à los sagrados ordenes. Buenos Ayres: En la Real Imprenta de los Niños Expositos, 1781, pp. 26-27. JCB BA781.S194cc.

44. AHN. Diversos, 37, n. 39. Carta desde Arequipa, 1765-04-12. 


\section{LA RED DE PROTECTORES}

El padre Yepes para «desvanecer las calumnias con que su Vicario General ha procurado desacreditarle» ${ }^{45}$ presentó una batería de documentos en su favor. Una de las más sorprendentes, por su peculiar imposibilidad de demostrar nada de lo que pretendía averiguarse, es la pesquisa e información del Cabildo de Buenos Aires ante el cual el propio Yepes presentó una retahíla de testigos que fueron desgranando pistas interesantes sobre su actividad en la ciudad. Todos ellos vinieron a decir que no comerció y que se dedicó a tareas misioneras, aunque cabría preguntarse, con cierta ironía, si el Cabildo y sus miembros eran los más adecuados para averiguar en asuntos de contrabando y, puestos al caso, si los testigos, comerciantes o soldados, pudieron decir algo distinto a lo que se les pidió. El resultado es revelador, comencemos, Isidro José Balbastro responde que «se ha mantenido en esta ciudad, sin que aia visto ni oído que se había metido en tratos de comercio de ningún modo" y que "ha hecho misión en la jurisdicción de la otra banda de este río", cumpliendo además con las obligaciones propias de su estado ${ }^{46}$. Es una declaración modélica. De todos modos es reveladora la actitud de algunos testigos, como Juan de Salinas que «necesitado de un juego de bolas de trucos con noticias que tuvo que dicho R. Pe traía unas fue a verle para comprarlas» pero Yepes le respondió que «las traía para llevar a su Provincia de Quito» ${ }^{47}$. Este testigo fue considerado en 1756 uno de los individuos calificados que podría cubrir el puesto de Juez de Comercio y era entonces un destacado miembro del Cabildo de Buenos Aires ${ }^{48}$. Forma parte de un grupo relativamente reducido que Socolow denomina «mercaderes porteños» a los que podemos considerar «the principal local beneficiaries of the Bourbon political and economic reforins of the late eighteenth century ${ }^{49}$.

Igualmente Eusebio de Sirer Cosio, comerciante, es preguntado y responde que sabe que "quando vino de España trajó unos caxones de libros y ornamentos para llevarlos a su Provincia de Quito». El informe final es una perla de descargo a favor de Yepes que «no se ha ejercitado en comercio

45. AGI. Quito, 288, nº 7. Esta cita y las siguientes.

46. AGI. Quito, 288, no 7. Testificación de Isidro José Balbastro. Buenos Aires, 2 de septiembre de 1767.

47. AGI. Quito, 288, no 7. Testificación de Juan de Salinas. Buenos Aires, 4 de septiembre de 1767.

48. M. J. Arazola Corvera, Hombres, barcos y comercio de la ruta Cádiz-Buenos Aires (17371757), Sevilla: Diputación, 1998, p. 302-303.

49. S. M. Socolow, «Economic Activities of the Porteño Merchants: The Viceregal Period», The Hispanic American Historical Review, 55, 1, 1975, p. 2. 
y otros actos que reprueben su estado y profesión sino que por el contrario, desde que llegó a esta ciudad se ha constantemente empleado en el bien y utilidad de los fieles, ya confesando y predicando en ella, y ya llevado de su celo en la otra banda de este río, a donde bautizó quarenta indios infieles y dispuso a los vecinos de aquellos partidos para que unidos en sociedad civil formasen en el Rosario una población»" ${ }^{50}$. Aunque el Cabildo advierte que, a pesar de todo, lo que sabía y sobre lo que podía informar era que «desembarcó en este riachuelo los mismos caxones que cargo en Cádiz, sobre el navío nombrado El Príncipe San Lorenzo", ahora bien "por lo que toca a si ha comerciado o no con ellos nada pueden certificar por no constarles lo uno ni lo otro». Más claro imposible, es una pesquisa breve y concisa que favorece a Yepes.

\section{LOS BREVES}

El 17 de junio de 1776 tres destacados mercedarios quiteños escribieron una representación al rey, entre ellos el Provincial Fr. José Bolaños, quejándose de Fr. José de Yepes. Este al retornar finalmente a su provincia quiteña presentó por «Breves pontificios y patentes que iba graduado de maestro, y padre de provincia de los que llaman de gracia, y de protonotario apostólico» ${ }^{51}$. La oposición dentro de la orden mercedaria fue contundente, pero el problema de jurisdicción quedó planteado obligando a una actuación de la Audiencia de Quito para averiguar y apaciguar los ánimos. Habían pasado 14 años desde la llegada de Yepes a Buenos Aires y continuaba enredando hasta el punto de que el fiscal recibió cartas de recomendación (al igual que había ocurrido anteriormente) ante lo cual advertía al Consejo que «Fr. Josef de Yepes tiene una travesura singular con la que no sólo sabe ocultar la verdad si no también hacer aparecer como evidentes las cosas que están muy distantes de lo cierto, valiéndose para ello de los medios que le parecen más a propósito, aunque no sean los más lícitos y decentes». De hecho, el fiscal señalaba que ni tan siquiera tenía el grado académico que pretendía o que llegó a falsificar documentos. Ante tal avalancha de dudas recomienda que «no es acreedor a que se le mantenga en los honores que con engańo obtuvo» ${ }^{52}$.

Un aspecto puntual, pero muy revelador, permite averiguar cómo desarrolló su estrategia. Ya vimos que el dinero recaudado a lo largo de

50. AGI. Quito, 288, n 7. Testificación de Eusebio de Sirer Cosio. Buenos Aires, 9 de septiembre de 1767.

51. AGI. Quito, 288, no 7.

52. AGI. Quito, 288, nº 7 . 
la peregrinación le permitió comprar las mercancías en España, entregar ornamentos a la ermita, etc. Aunque no podemos olvidar que a su vuelta a Quito parte de los bienes los aplicó directamente al convento mercedario de esta ciudad. El problema era que debía entregar a la ermita el dinero recaudado, ante lo cual presentó unas cuentas de liquidación realizadas por un amigo suyo y sin la presencia del comendador de la ermita. Yepes presentó copia de una carta de 22 de noviembre de 1777 en la que Fr. Fernando de Paredes, Provincial electo, y otros alababan su contribución a la ermita, a la que entregó «más de quarenta mil y quinientos pesos producto de su viaje y fatigas $»^{53}$. El asunto era tan poco claro que levantó las sospechas del fiscal que pidió se le secuestraran los bienes. Como vemos, Yepes tenía en todo momento una rara habilidad para enredar los asuntos y salir a flote otorgando favores, manipulando documentos y creando solidaridades que actuaran como escudos, en cierto modo burlándose de las autoridades seculares a través de artimañas y logrando crear discordia en su propia orden para obtener beneficios.

\section{LOS CAJONES DE LIBROS}

El envío de libros para constituir o ampliar bibliotecas en los conventos y colegios fue una estrategia empleada por las diferentes órdenes, en ocasiones como parte de un programa de formación para sus novicios, consolidación de sus cátedras universitarias, etc. ${ }^{54}$. Uno de los pocos casos analizados de las bibliotecas de las órdenes religiosas en el Quito colonial es el de la biblioteca del Colegio Máximo de los jesuitas. En el inventario de 1682 se anotaron 2.041 títulos resultando las materias más destacadas la patrística y los comentaristas bíblicos, con 462 títulos, y el derecho, con 364 títulos $^{55}$. Es de suponer que entre los libros seleccionados por Yepes para la biblioteca de la Orden de la Merced de Quito estuvieran también ampliamente representadas ambas rúbricas.

En el Sermon de la dedicacion del Templo de Nuestra Señora la Santissima Virgen de la Merced de la ciudad de Quito (1737) el predicador Ignacio de Chiriboga y Daza comparaba el remozado edificio «maravilla también de la

53. AGI. Quito, 288, no 7.

54. P. Rueda Ramírez, «La circulación de libros desde Europa a Quito en los siglos XVIXVII", Procesos. Revista Ecuatoriana de Historia, 15, 2000, p. 3-20.

55. Josep M. Barnadas, «La Biblioteca jesuita de Quito en el siglo XVII: Breve panorama analítico", Ibero-Americana Pragensia, 8, 1974, p. 155. 
América, y nuevo prodigio del Mundo nuevo ${ }^{56}$ con el Templo de Salomón y a los mercedarios con unos nuevos sabios, que "grandes han sido en los siglos que numera de duración los méritos de su sabiduría, ilustrando sus hijos, ya cándidos Cisnes, ya remontadas Águilas, la Iglesia, no menos con la sonora voz de la enseñanza, que con los provechosos documentos de la pluma ${ }^{57}$. Los escritos y lecturas formaban, de este modo, parte de una suma habilidad para «sazonar la sabiduría, y el amor» y formaban parte de su labor de «redempción de los hombres» ${ }^{58}$. La ampliación de la biblioteca que pretendía Yepes está conectada con una esta voluntad de adquirir reputación para la orden y ofrecer visibilidad a los saberes adquiridos.

En la carta citada del 22 de noviembre de 1777 los mercedarios quiteńos favorables a Yepes alababan su vida ejemplar, su virtud, etc. Y no olvidaban los beneficios que trajo su llegada en forma de nuevos ornamentos. Afirmaban que al "convento grande a obsequiado dos ornamentos enteros, quatro casullas sueltas, quatro capas de coro iguales, un paño de púlpito, un frontal, un arco de plata de más de dos varas de alto, diez quintales de fierro y sobre todo ha socorrido la extrema necesidad que teníamos de una biblioteca con cinquenta caxones de libros selectos en todo género de materias que es un don el más estimable para el adelantamiento literario de esta provincia» ${ }^{59}$. ¿Cuántos cajones llegaron a Quito? El Administrador de las Reales Alcábalas y de la Renta de Correos emitió un certificado, a petición de Fr. José de Yepes, según el cual el fraile trajo «de regreso de los reynos de Castilla y conducido a esta ciudad ciento y treinta piesas entre caxones de libros y ornamentos, y baúles, los rejistre en cumplimiento de mi obligación con la prolijidad pocible [sic] haciéndolas abrir en mi precencia [...] no encontramos sino libros, ornamentos de yglecia, ropa de su uso y otras cosas que no eran de comercio, ni debían pagar real alcábala» ${ }^{60}$.

Los 116 cajones de libros embarcados en Cádiz se convirtieron en los menguados 50 cajones entregados al convento, la diferencia de 66 cajones no desapareció por arte de magia, de hecho se vendieron para pagar los gastos

56. I. de Chiriboga y Daza, Sermones varios, que a diversas festividades de el año predicó en la ciudad de Quito el Doct. D. Ignacio de Chirivoga y Daza, canonigo de la Santa Iglesia Cathedral de Quito, y examinador synodal de aquel obispado, En Madrid: Por don Gabriel del Barrio, Impressor de la Real Capilla de su Magestad, 1739, p. 161

57. I. de Chiriboga y Daza, Sermones varios, que a diversas festividades de el año predicó en la ciudad de Quito, p. 179.

58. I. de Chiriboga y Daza, Sermones varios, que a diversas festividades de el año predicó en la ciudad de Quito, p. 179.

59. AGI. Quito, 288, no 7. Fr. Fernando de Paredes, Provincial electo, al Rey. Quito, 22 de noviembre de 1777.

60. AGI. Quito, 288, nº 7. 
del viaje. Es más, Yepes, al llegar a Quito, exigió que se le entregaran «cinco mil y más pesos que se debían a varios sujetos para los gastos de conducción de toda la carga y los precios de la subsistencia del mencionado Padre Maestro»" ${ }^{61}$. Al no poder la provincia pagarlos, según la versión interesada y favorable a Yepes, lo que hace dudar de su completa veracidad, resulta que le dieron autorización para la venta de «parte de los libros duplicados y otros efectos» que fueron entregados a don Francisco González de Evia ${ }^{62}$. De este modo quedaba diluido por completo el asunto y jamás sería posible averiguar si comerció o no con anterioridad. El propio Yepes en una extensa carta del 3 de marzo de 1779 exponía a su conveniencia el asunto, explicando que «no haviendo tenido este convento máximo el dinero para la satisfacción, fue necesario entregar a dicho acrehedor, parte de la misma carga, para que con su venta se verificase el pago de este crédito»" ${ }^{63}$. La actitud de Yepes forzando a su orden a aceptar los hechos consumados y exigiendo dinero o la autorización de la venta para garantizar la entrega de los bienes es muy reveladora de su taimada habilidad para manipular la situación y de cómo, finalmente, más de la mitad de los libros fueron vendidos en el mercado quiteño.

\section{Conclusiones}

El papel de Yepes en el trasiego atlántico de bienes resulta un tanto paradójico, su condición religiosa le otorgaba un estatus singular y le apartaba del tráfico comercial, pero a la par todos los condicionantes del prestigio asociado a su cargo le conferían la posibilidad de acumular limosnas e invertirlas en bienes de uso para su convento de Quito. Emplear el dinero recopilado en su viaje de Quito a Nueva España y de aquí a Espańa en 140 cajones (116 de ellos con libros) y viajar por la vía del Río de la Plata de retorno a Quito fue visto por el fiscal de la Corona como un acto de contrabando. En el pleito que se siguió durante varios años Yepes pudo articular un mecanismo de defensa basado en su proceder en Buenos Aires y alrededores, los documentos que llevaba acreditándole y, también, una extraordinaria facilidad para enredar a los miembros de su orden en luchas internas que le llevaron a provocar una auténtica rebelión en su estancia en el Río de la Plata y luego, de nuevo, una crisis interna en su orden a su llegada

61. AGI. Quito, 288, no 7.

62. AGI. Quito, 288, nº 7. Fr. Fernando de Paredes, Provincial electo, al Rey. Quito, 22 de noviembre de 1777.

63. AGI. Quito, 288, nº 7. 
a Quito con la carga. En cierto modo este mercedario actuó de manera similar a las oligarquías indianas que compraban cargos, adquirían un estatus privilegiado y se convertían en una pieza clave de las redes personales que estaban tras las actividades de negocio comercial. Sin el apoyo de estas redes (de su orden y de numerosos cargos públicos incluyendo al cabildo bonaerense) su defensa de las acusaciones de contrabandista no hubieran logrado su objetivo. Tal como advierte Moutoukias «los representantes de la corona se integraban a las oligarquías indianas en una única trama de actividades empresariales» ${ }^{64}$, algo que se ajusta perfectamente a la situación en la que se encontró Yepes a su llegada a Buenos Aires, con unos comerciantes que le visitaban con asiduidad, que le otorgaban préstamos y que declararon a su favor en todo momento, alabando su buen comportamiento y su labor en misiones. La conducta de Yepes fue, en este sentido, modélica, pues provenía de una experiencia de peregrinación con la imagen de la Virgen de una ermita quiteña y volvía para dotar a su convento de muebles y libros. El Yepes presentado por sus enemigos como contrabandista y enredador se diluía ante esta imagen devota de hombre entregado a ejercicios, devociones y prédicas elaborada por sus defensores. Aunque no le faltaron enemigos, incluyendo al vicario general de su orden, y a pesar de recibir órdenes de sus superiores sobre su regreso a Quito, nuestro fraile pudo destejer tales acusaciones y actuar, de nuevo, como muchos seglares, desobedeciendo de acuerdo a una lógica local de autoridad, lo cual le permitió inmiscuirse en el capítulo provincial, mantener el control sobre los 140 cajones y hacer su viaje tal como tenía planeado hasta Quito por una vía tan inusual como la de Buenos Aires. El camino fue, en cierto sentido, una estrategia que le permitió adquirir autonomía respecto a sus superiores, visitadores y los propios miembros de la orden en España y Roma, y le situó con ventaja a su llegada a Quito.

64. Z. Moutoukias, "Contrabando y sector externo en Hispanoamérica colonial», Para una historia de América, II: Los nudos 1, coord. Marcello Carmagnani, Alicia Hernández Chávez y Ruggiero Romano, México: El Colegio de México, 1999, p. 193. 


\section{BULLETIN HISPANIQUE}

\section{BibliografíA}

Arazola Corvera María Jesús, Hombres, barcos y comercio de la ruta Cádiz-Buenos Aires (1737-1757), Sevilla: Diputación, 1998.

Arazola Corvera María Jesús, «El mundo del comercio vasco-navarro en la ruta del Plata. Los registros sueltos», Itsas Memoria. Revista de Estudios Maritimos del País Vasco, 4, 2003, p. 327-342.

Asdrúbal Silva Hernán, El comercio entre España y el Río de la Plata (1778-1810), Madrid: Banco de España, 1993.

Barnadas Josep M., «La Biblioteca jesuita de Quito en el siglo XVII: Breve panorama analítico", Ibero-Americana Pragensia, 8, 1974, p. 151-161.

Calvo Carlos, Colección completa de los tratados, convenciones, capitulaciones, armisticios y otros actos diplomáticos de todos los Estados de la América Latina comprendidos entre el Golfo de Méjico y el Cabo de Hornos, desde el año de 1493 hasta nuestros dias, Vaduz (Liechtenstein) : Topos Verlag, 1978, 16 v. Facsímil de la ed. de Paris, 1862-1869.

Carta circular, ò edicto, de el ilustrisimo, y reverendisimo señor D. Fr. Josef Antonio de S. Alberto, del consejo de S.M. y obispo de Cordova del Tucuman: dirigida a todos sus amados hijos, y diocesanos, que desean, y solicitan, y que en adelante solicitaren ser promovidos à los sagrados ordenes. Buenos Ayres : En la Real Imprenta de los Niños Expositos, 1781.

Chiriboga y Daza Ignacio de, Sermones varios, que a diversas festividades de el año predicó en la ciudad de Quito el Doct. D. Ignacio de Chirivoga y Daza, canonigo de la Santa Iglesia Cathedral de Quito, y examinador synodal de aquel obispado, En Madrid: Por don Gabriel del Barrio, Impressor de la Real Capilla de su Magestad, 1739.

Du Biscay Acarete, Voyage dv Sr. Acarette a Bvenos-Ayres svr la Riviere de la Plate, \& delà au Perou. Et l'Indien ov portrait av natvrel des Indiens presenté au Roy d'Espagne par D. Iüan de Palafox Evesque de la Puebla de los Angeles, A Paris: Chez André Cramoisy, 1672.

El contrabando y el comercio exterior en la Nueva España, nota preliminar de Ernesto de la Torre Villar; advertencia de Luis Chácez Orozco, México: Publicaciones del Banco Nacional de Comercio Exterior, 1967. (Colección de documentos para la historia del comercio exterior de México, segunda serie, IV).

Leonard Irving A., "Spanish Ship-Board Reading in the Sixteenth", Hispania, 32, 1, 1949, p. 53-58.

López François, "Geografía de la edición. El comercio interior y exterior», Historia de la edición y de la lectura en España, 1472-1914, Madrid, 2003, p. 338-347.

López-Vidriero María Luisa, "Le rôle de l'Espagne dans le commerce du livre au XVIII ${ }^{e}$ siècle», Le Livre voyageur: constitution et dissémination des collections livresques dans l'Europe moderne, 1450-1830, éd. Dominique Bougé-Grandon, Paris: Klincksieck, 2000, p. 129-151. 
Malamud Rikles Carlos Daniel, Cádiz y Saint-Malo en el comercio colonial peruano (1698-1725), Cádiz: Diputación, 1986.

Martini Mónica P., «Los libros destinados al convento de monjas de Santa Catalina de Siena de Buenos Aires», III Congreso Argentino de Americanistas. Año 1999, Buenos Aires: Sociedad Argentina de Americanistas, 2000, t. I, p. 175-190.

Molleda Ma Dolores G., «El contrabando inglés en América: correspondencia inédita de la factoría de Buenos Aires», Hispania, 10, 39, 1950, p. 336-369.

Moutoukias Zacarías, Contrabando y control colonial en el siglo XVII: Buenos Aires, el Atlántico y el espacio peruano, Buenos Aires: Centro Editor de América Latina, 1988.

- «Contrabando y sector externo en Hispanoamérica colonial», Para una historia de América, II: Los nudos 1, coord. Marcello Carmagnani, Alicia Hernández Chávez y Ruggiero Romano, México: El Colegio de México, 1999, p. 172-197.

Muñoz Pérez José, «Mapa aduanero del XVIII español», Estudios geográficos, 16, 61, 1955, p. 747-797.

Ortiz de Zuñiga Diego, Anales eclesiásticos y seculares [1796], Sevilla: Guadalquivir, 1988.

Palomo F., «Limosnas impresas. Escritos e imágenes en las prácticas misioneras de interior en la península Ibérica (siglos XVI-XVIII)", Manuscrits: Revista d'història moderna, 25, 2007, p. 239-265.

Parada Alejandro E., "La nueva historia del libro y las bibliotecas en la Argentina: antecedentes, historia y periodización», Congreso Mundial de Bibliotecas e Información: $70^{\circ}$ Congreso General y Consejo de la IFLA . Bibliotecas: Instrumentos para la Educación y el Desarrollo. 22 al 27 de Agosto del 2004, Buenos Aires, Argentina. http://www.ifla.org/IV/ifla70/prog04.htm [Consulta: 30/05/2009].

Perusset Veras Macarena, "Comportamientos al margen de la ley: contrabando y sociedad en Buenos Aires en el siglo XVII», Historia crítica, 33 (2007), p. 158185.

Rahn Phillips Carla, «Mercado, modas y gustos: los cargamentos de ida y vuelta en el comercio atlántico de España», España y América: Un océano de negocios. Quinto centenario de la Casa de la Contratación, 1503-2003, [Madrid]: Sociedad Estatal de Conmemoraciones Culturales, 2003, p. 187-202.

Recio Bernardo, Compendiosa relación de la cristiandad de Quito, Madrid: Consejo Superior de Investigaciones Científicas, Instituto Santo Toribio Mogrovejo, 1947.

Rípodas Ardanaz D., Un ilustrado cristiano en la magistratura indiana: Antonio Porlier, Marqués de Bajamar. Viaje de Cádiz a Potosi (1758-1759), Buenos Aires: PRHISCO-CONICET, 1992.

- «Introducción fraudulenta de libros prohibidos en el Río de la Plata (1788)», Revista de historia del derecho, 28, 2000, p. 503-512.

Rodríguez García Margarita Eva, Compañias privilegiadas de comercio con América y cambio político (1706-1765), Madrid: Banco de España, 2005. 
Rueda Ramírez Pedro, «El contrabando de libros en la Carrera de Indias: una faceta poco conocida del comercio del libro", Testigo del tiempo, memoria del universo. Cultura escrita y sociedad en el mundo ibérico (siglos XV-XVIII), comp. Manuel F. Fernández, C. A. González Sánchez, N. Maillard, [Barcelona]: Ediciones Rubeo, 2009, p. 153-174.

- «La circulación de libros desde Europa a Quito en los siglos XVI-XVII», Procesos. Revista Ecuatoriana de Historia, 15, 2000, p. 3-20.

Migden Socolow Susan, «Economic Activities of the Porteño Merchants: The Viceregal Period», The Hispanic American Historical Review, 55, 1, 1975, p. 1-24.

Torre Revello José, «Lista de libros embarcados para Buenos Aires en los siglos XVII y XVIII», Boletín del Instituto de Investigaciones Históricas, X, 43-44, 1930, p. 2850 .

- El Libro, la imprenta y el periodismo en América durante la dominación española, México: Universidad Nacional Autónoma de México, 1991.

Ulloa Modesto, La Hacienda Real de Castilla en el reinado de Felipe II, $3^{\mathrm{a}}$ ed. revisada, Madrid: Fundación Universitaria Española, 1986.

Villalobos R. Sergio, Comercio y contrabando en el Río de la Plata y Chile, 17001811, Buenos Aires: Editorial Universitaria de Buenos Aires, 1965. 